\title{
Isolation and characterization of potent antifungal strains of the Streptomyces violaceusniger clade active against Candida albicans
}

\author{
Min J. Kang · Janice L. Strap · Donald L. Crawford
}

Received: 12 May 2009/Accepted: 10 September 2009/Published online: 26 September 2009

(C) The Author(s) 2009. This article is published with open access at Springerlink.com

\begin{abstract}
Streptomyces strains were isolated from a sagebrush rhizosphere soil sample on humic acid vitamin (HV) agar and water yeast extract (WYE) agar supplemented with $1.5 \%(\mathrm{w} / \mathrm{w})$ phenol as a selective medium. Acidic, neutral and alkaline $\mathrm{pH}$ conditions were also used in the isolation procedures. The phenol treatment reduced the numbers of both actinomycetes and non-actinomycetes on plates under all three $\mathrm{pH}$ conditions. From phenol-amended HV and WYE agar, 16 strains were isolated in pure culture; 14 from the HV agar and two from the WYE agar. All the isolates were tested for their antifungal activities against Pythium ultimum P8 and five yeast strains, including two antifungal drug-resistant Candida albicans strains. HV isolates that showed broad-spectrum antifungal antibiotic activities were all found to be members of the Streptomyces violaceusniger clade, while those that did not were non-clade members. The phenol treatment was not selective for $S$. violaceusniger clade members. Therefore, we tested the spores of both S. violaceusniger clade and non-clade members using two biocides, phenol and hydrogen peroxide, as selection agents. Spores of non-clade members, such as $S$. coelicolor M145 and S. lividans TK 21, survived these two biocides just as
\end{abstract}

M. J. Kang $(\bowtie)$

Department of Chemistry and Biochemistry,

University of California at San Diego,

9500 Gilman Drive, La Jolla, CA 92093-0358, USA

e-mail: mjkang@ucsd.edu

J. L. Strap

Faculty of Science, University of Ontario Institute

of Technology, Oshawa, ON L1K 2Z1, Canada

D. L. Crawford

Department of Microbiology, Molecular Biology

and Biochemistry, University of Idaho, Moscow,

ID 83844-3052, USA well as $S$. violaceusniger clade members. Thus, in our hands, biocide resistance was not $S$. violaceusniger clade specific as previously reported. However, isolates showing broadspectrum antifungal and antiyeast activity were all members of the clade. We conclude that screening of isolates for broad-spectrum antifungal/antiyeast activity is the preferred method of isolating S. violaceusniger clade strains rather than biocide-based selection. Phylogenetic analysis of the phenol-resistant isolates revealed that the $\mathrm{HV}$ isolates that exhibited broad-spectrum antifungal antibiotic activity were all clustered and closely related to the $S$. violaceusniger clade, while the isolates that did not exhibit antifungal antibiotic activity were all non-clade members.

Keywords Streptomyces violaceusniger clade . Antifungal antibiotics $\cdot$ Candida albicans

\section{Introduction}

Members of the Streptomyces violaceusniger clade are known to be antagonistic to many different classes of plant pathogenic fungi $[14,17,18]$. This clade includes four recognized species, S. hygroscopicus, S. melanosprofaciens, S. sparsogenes, and S. violaceusniger [11, 20]. Although these species are assigned to the same clade, they are differentiated into different DNA homology groups [11]. One strain, S. violaceusniger YCED-9, isolated by our own laboratory, has been shown to produce at least three different antifungal antibiotics, including nigericin, geldanamycin, and a polyene-like compound similar to guanidylfungin A [17]. This strain is able to inhibit Fusarium, Pythium, and Phytophthora spp. [17]. It also produces chitinases and $\beta$-1,3-glucanase enzymes that are induced by the presence of fungal cell walls [17]. Another 
strain, isolated by our lab, S. violaceusniger WYE53, also expresses strong antibiotic activities against turfgrass fungal pathogens, including Pythium ultimum, Fusarium oxysporium, Rhizoctonia solani, Sclerotina homeocarpa, Gaeumannomyces graminis and Microdochium nivale. These fungi cause diseases in golf course turfgrass, and S. violaceusniger strains WYE53 and YCED-9 effectively control the diseases $[3,4]$.

Streptomyces violaceusniger and S. hygroscopicus are both clade members. From our own research and the accumulated literature, members of this clade could be the most effective antifungal Streptomyces biocontrol agents isolated from different geographical regions, and they could be used as effective protectors of plants from fungal root diseases [3, 4, 19].

Thus, this clade is a likely source of Streptomyces that produce potent antifungal agents with the potential for medical applications in the treatment of invasive fungal infections. Therefore, we hypothesized that this Streptomyces clade represents an important Streptomyces group that naturally protects plants against fungal root pathogens in nature, and that they are a potential source of new antifungal agents that may also be effective in protecting humans against invasive fungal diseases. Because it has previously been shown that pretreatment of soils with phenol is a good method of selecting the $S$. violaceusniger clade [9], this study also used phenol selection to target the isolation of $S$. violaceusniger clade members in the soil and screened those strains that survived the phenol pretreatment for their strength and spectrum of antifungal and antiyeast activity against a panel of medically important, drug-resistant yeasts. These findings should facilitate better isolation methods for characterizing potentially important antibiotic producers.

\section{Materials and methods}

Soil enrichment procedures

One gram of rhizosphere soil was obtained from a sagebrush plant (Artemisia tridentate) near Lewiston, ID, in October 2004 using previously described methods [7]. The soil sample was then pretreated with $1.5 \%(\mathrm{w} / \mathrm{w})$ of phenol (Fisher Scientific) at $30^{\circ} \mathrm{C}$ for $30 \mathrm{~min}$ with occasional stirring according to the method of Hayakawa et al. [9]. Serial dilutions of treated samples were prepared in sterile physiological saline and inoculated onto duplicate plates of humic acid-vitamin (HV) agar medium according to the method of Hayakawa et al. [9]. Samples pretreated with phenol were also inoculated onto water yeast extract (WYE) agar [1]. As a control, untreated samples were also inoculated onto HV and WYE agar. Humic acid-vitamin agar was prepared as described previously [8]. It is a minimal medium containing $\mathrm{Na}_{2} \mathrm{HPO}_{4} 0.05 \%$; $\mathrm{KCl} 0.17 \%, \mathrm{MgSO}_{4} \cdot 7 \mathrm{H}_{2} \mathrm{O} 0.005 \%$, FeS$\mathrm{O}_{4} \cdot 7 \mathrm{H}_{2} \mathrm{O} 0.001 \%, \mathrm{CaCO}_{3} 0.002 \%$ at $\mathrm{pH} 7.2$, supplemented with $0.1 \%$ (w/v) of humic acid (Sigma Chemicals) as carbon source. The vitamin solution $(0.00005 \%$ each of thiamine $\mathrm{HCl}$, riboflavin, niacin, pyridoxine- $\mathrm{HCl}$, inositol, Ca-pantothenate, $p$-aminobenzoic acid, and $0.000025 \%$ of biotin) was made separately, filter sterilized, and added after the medium was autoclaved.

Three sets of $\mathrm{pH}$ conditions were evaluated, including an acidic pretreatment of $\mathrm{pH} 3$ using phosphate buffer $(\mathrm{pH} 3.0)$, a basic pretreatment $(\mathrm{pH} \mathrm{8.0)}$ in Tris- $\mathrm{HCl}$ buffer, and a neutral pretreatment ( $\mathrm{pH}$ 7.0) in phosphate buffer. After incubation at $30^{\circ} \mathrm{C}$ for 14 days, colonies were picked for pure culture isolation. These experiments were performed to see whether $\mathrm{pH}$ affected the success of selection for $S$. violaceusniger clade members. In each of the different $\mathrm{pH}$ conditions, the colony forming units/gram (CFU/g) of actinomycetes and non-actinomycetes were also enumerated.

Isolation of phenol-resistant colonies from HV agar

Once phenol-pretreated colonies were growing on the HV and WYE agar, individual colonies were transferred onto yeast extract malt extract dextrose (YEMED) agar [1] for further maintenance and analysis.

Antifungal and antiyeast activities of phenol-resistant isolates

The isolates were tested for their activities against the phytopathogenic fungus Pythium ultimum P8 (laboratory strain), and five yeast strains, including Candida albicans (ATCC 90027), Saccharomyces cerevisiae (laboratory strain), Saccharomyces pastorianus (ATCC 2366), and two drug-resistant yeasts, C. albicans sp. ATCC MY-204276 (fluconazole resistant) and C. albicans ATCC 44373 (5-fluorocytosine resistant).

Streptomyces strains were inoculated onto the centers of potato dextrose agar (PDA) and yeast dextrose agar (YDA) plates to test the antifungal and antiyeast activities. The cultures were incubated at $28^{\circ} \mathrm{C}$ for 7 days to allow for growth, sporulation and the production and diffusion of metabolites. A PDA agar block $\left(0.5 \mathrm{~cm}^{2}\right)$ containing actively growing fungal mycelium was then aseptically placed on one side of the plate [5]. For antiyeast activities, the test strains were streaked perpendicularly to the sporulated Streptomyces culture on the other half side of the plate. Plates were incubated for 24 and $48 \mathrm{~h}$ and examined at each time for inhibition of the growth of the fungus and yeasts. Fungal mycelial plugs and yeasts were inoculated alone, without the Streptomyces, as controls. Inhibition was indicated when fungal mycelial growth in the direction of the 
Table 1 Sagebrush rhizosphere soil treatment with phenol at three different pHs

\begin{tabular}{|c|c|c|c|}
\hline & $\begin{array}{l}\text { Actinomycetes } \\
(\mathrm{CFU} / \mathrm{g})\end{array}$ & $\begin{array}{l}\text { Non-actinomycetes } \\
\text { (CFU/g) }\end{array}$ & Final pH (in soil) \\
\hline Sample \#1 (phosphate buffer $\mathrm{pH} 7.0$ without phenol) & $6.5( \pm 1.1) \times 10^{5}$ & $4.3( \pm 0.7) \times 10^{7}$ & 7.2 \\
\hline Sample \#2 (phosphate buffer pH 7.0 with phenol) & $1.3( \pm 0.2) \times 10^{5}$ & $3.3( \pm 1.1) \times 10^{4}$ & $\begin{array}{l}7.0 \text { (after addition } \\
\text { of phenol) }\end{array}$ \\
\hline Sample \#3 (base treatment; Tris- $\mathrm{HCl}$ pH 8.0 without phenol) & $1.9( \pm 0.3) \times 10^{6}$ & $1.2( \pm 0.2) \times 10^{7}$ & 7.7 \\
\hline Sample \#4 (base treatment; Tris- $\mathrm{HCl}$ pH 8.0 with phenol) & $7.8( \pm 0.4) \times 10^{4}$ & $9.1( \pm 2.6) \times 10^{6}$ & $\begin{array}{l}7.4 \text { (after addition } \\
\text { of phenol) }\end{array}$ \\
\hline Sample \#5 (acid treatment; phosphate buffer pH 3.0 without phenol) & $1.7( \pm 0.1) \times 10^{6}$ & $4.8( \pm 0.4) \times 10^{6}$ & 3.3 \\
\hline Sample \#6 (acid treatment; phosphate buffer pH 3.0 with phenol) & $7.0( \pm 2.8) \times 10^{4}$ & $5.0( \pm 4.2) \times 10^{6}$ & $\begin{array}{l}3.3 \text { (after addition } \\
\text { of phenol) }\end{array}$ \\
\hline
\end{tabular}

Streptomyces colony was retarded or prevented as compared with a control plate inoculated with fungus alone.

16S rDNA amplification for species identification

To identify the strains, phenol-resistant colonies in pure culture were grown in YEME liquid medium, and genomic DNA was prepared by the procedures of Hopwood et al. [10]. 16S rDNA was amplified from the genomic DNA using oligonucleotide primers targeting conserved sequences in the $3^{\prime}$ and $5^{\prime}$ regions of bacterial $16 \mathrm{~S}$ rDNA. The forward primer was $27 \mathrm{~F}$ and the reverse primer was $1525 \mathrm{R}$ [12]. Each PCR mixture contained $20 \mathrm{pM}$ of each primer, $0.2 \mathrm{mM}$ of dNTPs, $2.5 \mathrm{mM}$ of $\mathrm{MgCl}_{2}, 5 \mu \mathrm{l}$ of 10X PCR reaction buffer (Invitrogen, Carlsbad, CA, USA), $1 \mu \mathrm{g}$ of genomic DNA as a template, and 1U of Taq DNA polymerase (Invitrogen) to a final volume of $50 \mu \mathrm{l}$. The PCR reaction conditions were as follows: $5 \mathrm{~min}$ at $95^{\circ} \mathrm{C}$ for one cycle followed by 30 cycles of $1 \mathrm{~min}$ each at $95^{\circ} \mathrm{C}, 1 \mathrm{~min}$ at $55^{\circ} \mathrm{C}$, and 2 min at $72^{\circ} \mathrm{C}$, and finally one cycle for $7 \mathrm{~min}$ at $72^{\circ} \mathrm{C}$, in a PTC-programmable thermal controller (MJ Research, Inc.). The amplified PCR product (expected size was 1,500 base pairs) was purified by MOBIO gel purification filters (MO BIO Laboratories, Carlsbad, CA, USA) and ligated into the pCR-4 TOPO cloning vector (Invitrogen), and then transformed into chemically competent Top10 E. coli. Sequencing was performed at the Washington State University (Pullman, WA, USA) sequencing facility.

Phenol pretreatment with Streptomyces spore suspensions

It has been reported that the spores of $S$. violaceusniger clade members are resistant to phenol treatment [9]. To examine this trait of biocide resistance, we treated taxonomically known Streptomyces spore suspensions with $1.5 \%(\mathrm{w} / \mathrm{w})$ phenol and $0.1 \%(\mathrm{w} / \mathrm{w})$ hydrogen peroxide, and tested their survival. Five type strains of the $S$. violaceusniger clade (S. hygroscopicus NRRL 2339, S. hygroscopicus NRRL
B-1477, S. melanosporofaciens NRRL B-12234, Streptomyces spp. EF76, and S. violaceusniger NRRL-5563) and three non-clade type strains (S. lydicus NRRL ISP-5461, S. coelicolor M145, and S. lividans TK 21) were compared in this survival test. The $S$. coelicolor M145 and S. lividans TK21 strains were kindly given to us as a gift by Mark J. Buttner from the John Innes Institute, Norwich, UK. For this test, a spore suspension of each streptomycete strain was quantified by dilution plate counting prior to the experiment to check their viability. Once the spore suspension was quantified, spores were washed with $10.3 \%$ (w/v) sucrose three times to get rid of residual glycerol from the $20 \%(\mathrm{w} / \mathrm{v})$ glycerol spore stocks, and then $1.5 \%(\mathrm{w} / \mathrm{w})$ phenol (Fisher Scientific, Fair Lawn, NJ, USA) or hydrogen peroxide (J.T. Baker Chemical Co., Phillipsburg, NJ, USA) was added to the spore suspension that had been aseptically suspended in sterile $5 \mathrm{mM}$ phosphate buffer ( $\mathrm{pH}$ 7.0) to give a final density of $10^{6} \mathrm{CFU} / \mathrm{ml}$. The suspension was then incubated at $30^{\circ} \mathrm{C}$ for $30 \mathrm{~min}$ with occasional mixing. Untreated spore suspensions were used as controls. After incubation, samples were serially diluted in sterile water and plated in triplicate on HV agar and YEMED agars. The plates were incubated at $30^{\circ} \mathrm{C}$ until they developed sporulated colonies. Spore survival was expressed as colony forming units per $\mathrm{ml}(\mathrm{CFU} / \mathrm{ml})$ in the treated samples, as compared with the $\mathrm{CFU} / \mathrm{ml}$ number in untreated suspensions [9].

Phylogenetic analysis of isolates

The 16S rDNA sequences of the test strains were aligned with the 16S rDNA sequences of other Streptomyces retrieved from the EMBL/Gen Bank database. The vector NTI (version 9.0, Invitrogen) program was used as an editing tool. Multiple alignments were obtained manually using the Clustal X 1.8 program [16]. Neighbor-joining phylogenetic trees were inferred using the PAUP package [15] on a SG1 computer. Bootstrap analyses of the neighbor-joining method data based on 1,000 re-samplings was generated using the PAUP package [15]. 
Table 2 Antifungal activities of phenol-resistant isolates on PDA and YDA media

\begin{tabular}{|c|c|c|c|c|c|c|c|c|c|c|c|c|}
\hline \multirow{2}{*}{$\begin{array}{l}\text { Test strains } \\
\text { isolates } \\
\text { Media }\end{array}$} & \multicolumn{2}{|c|}{ P. ultimum } & \multicolumn{2}{|c|}{ S. cerevisiae } & \multicolumn{2}{|c|}{ S. pastrorianus } & \multicolumn{2}{|c|}{ C. albicans 90027} & \multicolumn{2}{|c|}{$\begin{array}{l}\text { C. albicans } \\
\text { ATCC } 44373\end{array}$} & \multicolumn{2}{|c|}{$\begin{array}{l}\text { C. albicans } \\
\text { MY } 204276\end{array}$} \\
\hline & PDA & YDA & PDA & YDA & PDA & YDA & PDA & YDA & PDA & YDA & PDA & YDA \\
\hline HV 1 & 0 & 4 & 0 & 0 & 0 & 0 & 0 & 0 & 0 & 0 & 0 & 0 \\
\hline HV 2 & 0 & 0 & 0 & 0 & 0 & 0 & 0 & 0 & 0 & 0 & 0 & 0 \\
\hline HV 3 & 0 & 0 & 5 & 0 & 5 & 0 & 0 & 0 & 0 & 0 & 0 & 0 \\
\hline HV 4 & 0 & 0 & 0 & 0 & 0 & 0 & 0 & 0 & 0 & 0 & 0 & 0 \\
\hline HV 5 & 23 & 7 & 0 & 0 & 0 & 0 & 0 & 0 & 0 & 0 & 0 & 0 \\
\hline HV 6 & 0 & 0 & 0 & 0 & 0 & 0 & 0 & 0 & 0 & 0 & 0 & 0 \\
\hline HV 7 & 0 & 0 & 0 & 0 & 0 & 0 & 0 & 0 & 0 & 0 & 0 & 0 \\
\hline HV 8 & 13 & 14 & 20 & 22 & 19 & 23 & 15 & $* * *$ & 18 & 22 & 18 & $* * *$ \\
\hline HV 9 & 18 & 15 & 22 & $* * *$ & 23 & 20 & 0 & 9 & 4 & 10 & 4 & 6 \\
\hline HV 10 & 14 & 16 & 17 & 10 & 19 & $* * *$ & 5 & 0 & 7 & 14 & 6 & 9 \\
\hline HV 11 & 19 & 0 & 0 & 0 & 0 & 0 & 0 & 0 & 0 & 0 & 0 & 0 \\
\hline HV 12 & 14 & 13 & 26 & 15 & 22 & 24 & 5 & 15 & 5 & 20 & 6 & 16 \\
\hline HV 14 & 10 & 0 & 0 & 0 & 0 & 0 & 0 & 0 & 0 & 0 & 0 & 0 \\
\hline HV 15 & 15 & 0 & 0 & 0 & 0 & 0 & 0 & 0 & 0 & 0 & 0 & 0 \\
\hline WYE 1 & 23 & 22 & 15 & 28 & 20 & 20 & 32 & 31 & 32 & 30 & 29 & $* * *$ \\
\hline WYE 2 & $* * *$ & $* * *$ & 15 & 15 & 22 & 23 & 31 & 32 & 31 & 30 & $* * *$ & $* * *$ \\
\hline
\end{tabular}

Zone of inhibition was measured in $\mathrm{mm}$ after 48 hours of incubation

*** No growth of inoculated fungus and yeast strains due to complete inhibition

Table 3 Identification of phenol-resistant isolates by $16 \mathrm{~S}$ rDNA analysis

\begin{tabular}{lll}
\hline $\begin{array}{l}\text { Sequences } \\
\text { isolates }\end{array}$ & BLAST match & $\begin{array}{l}\text { \% of nucleotide } \\
\text { sequence identity }\end{array}$ \\
\hline HV 1 & S. tumenensis & $98(898 / 916 \mathrm{bp})$ \\
HV 3 & S. paradoxus & $98(1,462 / 1,477 \mathrm{bp})$ \\
HV 4 & S. scabies & $98(1,493 / 1,520 \mathrm{bp})$ \\
HV 5 & Streptomyces spp. SM22 & $99(1,502 / 1,517 \mathrm{bp})$ \\
HV 7 & S. flavariabilis & $98(1,460 / 1,483 \mathrm{bp})$ \\
HV 8 & S. hygroscopicus & $99(1,475 / 1,479 \mathrm{bp})$ \\
HV 10 & S. violaceusniger & $98(1,465 / 1,489 \mathrm{bp})$ \\
HV 12 & S. violaceusniger & $98(1,450 / 1,474 \mathrm{bp})$ \\
HV 14 & S. scabies & $98(1,491 / 1,515 \mathrm{bp})$ \\
WYE 1 & S. hygroscopicus & $99(1,469 / 1,473 \mathrm{bp})$ \\
WYE 2 & S. hygroscopicus & $99(1,469 / 1,474 \mathrm{bp})$ \\
\hline
\end{tabular}

\section{Results}

Soil enrichment with phenol and effect of $\mathrm{pH}$ on isolation procedures

Three different $\mathrm{pH}$ ranges were used for isolation using phenol pretreatment and $\mathrm{HV}$ agar for the selection of S. violaceusniger clade members. The $\mathrm{pH}$ of the soil was 7.3 and that of the phenol solution was 6.7. The $\mathrm{pH}$ was measured before and after the addition of phenol into the soil-inoculated solutions.

The results for six different sets of $\mathrm{pH}$ conditions are shown in Table 1. With phenol treatment of the soil, total actinomycete numbers decreased compared to untreated samples. Numbers of non-actinomycete bacteria were also reduced by the phenol treatment except under the acidic conditions. $\mathrm{pH}$ did not have a large effect on CFUs/g. The CFUs/g numbers were similar under acidic, basic and neutral isolation conditions. However, the CFUs/g number was generally decreased by phenol treatment. The results show that phenol is a good biocide to eliminate abundant and dominant species in the soil while leaving phenolresistant actinomycete colonies for isolation and characterization. Isolates grew more slowly on HV agar than on WYE agar, and colony shapes, colors and morphologies were also different. Otherwise, the results were similar to $\mathrm{HV}$ agar. One interesting observation was that no slimeforming eubacterial colonies grew on the HV agar, while the WYE agar had many of these types of colonies. Since changing the $\mathrm{pH}$ did not affect the CFUs/g number in these experiments, we recommend the use of a neutral $\mathrm{pH}$ for such studies.

Isolation of phenol resistance colonies

From the phenol-treated soil sample, 14 colonies were isolated from $\mathrm{HV}$ agar and two colonies were isolated from 


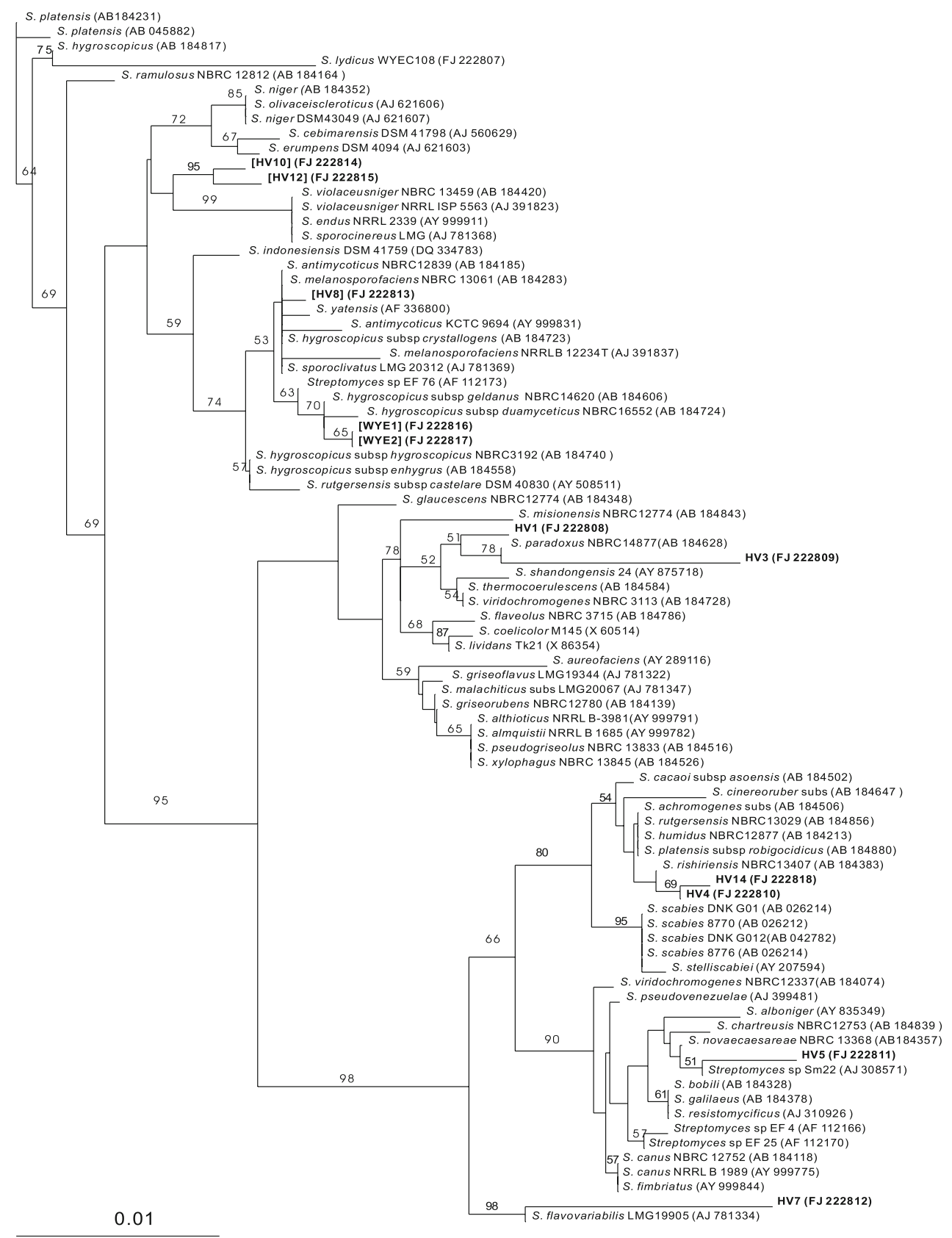

Fig. 1 Neighbor-joining tree based on almost complete 16S rDNA sequences of $\mathrm{HV}$ isolates and related strains. The numbers at the nodes indicate percentages of bootstrap support $(n=1,000$

WYE agar. All of the isolates were picked based upon their streptomycete-like morphologies and excellent sporulation, and were streaked onto the YEMED agar for growth as pure cultures until all were well developed and sporulated.

Antifungal and antiyeast activities of isolates

Antifungal activities and antiyeast activities were measured on the same plate on two media (Table 2). Isolates HV-1 resamplings); only values over $50 \%$ are given. The scale bar corresponds to 0.01 nucleotide substitutions per site. The clade members are shown in square brackets

through HV-7 did not show any antifungal activities or antiyeast activities, although HV-1 and HV-5 moderately inhibited P. ultimum P8. HV-8, 9, 10 and 12 showed broadspectrum activity against all of the test strains. These strains strongly inhibited the drug-resistant strains, C. albicans ATCC 44373 (5-fluorocytosine resistant) and C. albicans MY 204276 (fluconazole resistant). HV-11, 14, and 15 inhibited only $P$. ultimum P8. WYE isolates 1 and 2 showed broad-spectrum activity against all of the test strains. 
16S rDNA amplification for strain identification

All the isolates were identified with almost complete $16 \mathrm{~S}$ rDNA sequences. Each sequence was subjected to a BLAST search. Table 3 summarizes the identities of the HV and WYE agar isolates. Interestingly, the broad-spectrum antibiotic producers, such as HV-8 and 10, matched with high sequence identity to $S$. violaceusniger clade members, while the characterized strains that did not show antifungal and antiyeast activities were identified as non-clade members.

These data support our hypothesis that broad-spectrum antifungal antibiotic producers tend to be members of the $S$. violaceusniger clade. Phylogenetic analysis based on the neighbor-joining tree (Fig. 1) showed that the isolates that exhibit broad-spectrum antifungal antibiotic producers were all clustered together and were clade members, while those that did not show antifungal activities were non-clade members and were clustered together. The strains that survived the phenol treatment but were identified as nonclade members did not exhibit antifungal activities. The phenol treatment did not specifically enrich for members of the $S$. violaceusniger clade.

Phenol pretreatment with Streptomyces spore suspensions

Spores of five $S$. violaceusniger clade members ( $S$. hygroscopicus NRRL 2339, S. hygroscopicus NRRL B-1477, S. melanosporofaciens NRRL B-12234, Streptomyces spp. EF76, and S. violaceusniger NRRL-5563) and three nonclade members (S. lydicus NRRL ISP-5461, S. coelicolor M145, and S. lividans TK 21) were tested for their ability to survive two biocide treatments. All of the $S$. violaceusniger clade members survived the $1.5 \%(\mathrm{w} / \mathrm{w})$ phenol and $0.1 \%(\mathrm{w} / \mathrm{w})$ hydrogen peroxide treatment except for S. violaceusniger NRRL 5563 (Figs. 2 and 3).

Since $S$. violaceusniger NRRL 5563 did not sporulate, it was, as expected, unable to survive the biocides. Interestingly, the non-clade members $S$. coelicolor M145 and

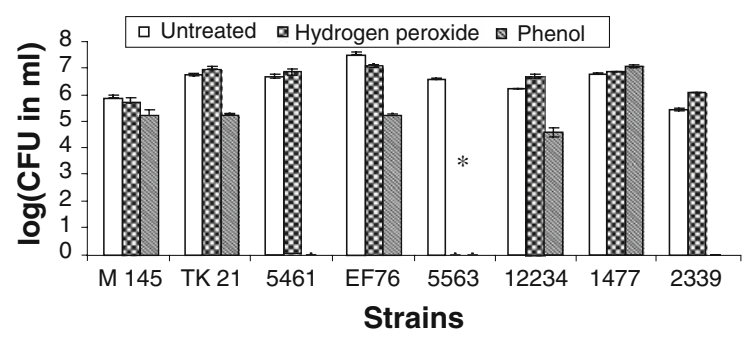

Fig. 2 Biocide experiment in which Streptomyces strains were untreated, treated with hydrogen peroxide $(0.1 \%, \mathrm{w} / \mathrm{w})$, or treated with phenol $(1.5 \%, \mathrm{w} / \mathrm{w})$ and then grown on $0.1 \%$ humic acid vitamin (HV) agar. Error bars show standard errors for duplicate experiments. * S. violaceusniger 5563 is a non-sporulator

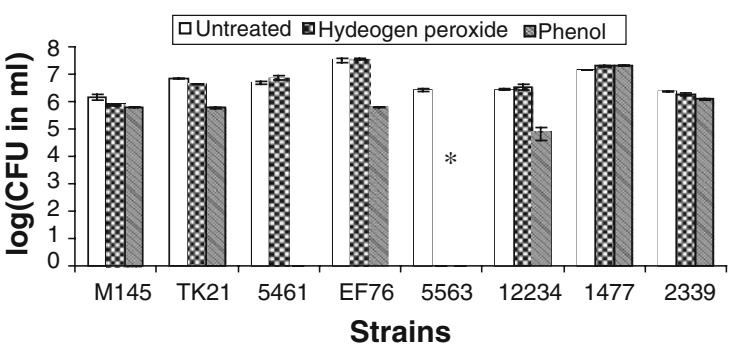

Fig. 3 Biocide experiment in which Streptomyces strains were either untreated, treated with hydrogen peroxide $(0.1 \%$, w/w), or treated with phenol $(1.5 \%, \mathrm{w} / \mathrm{w})$ and then grown on yeast extract malt extract dextrose (YEMED) agar. Error bars show standard deviations for duplicate experiments. ${ }^{*}$ S. violaceusniger 5563 is a non-sporulator

S. lividans TK 21 also showed biocide resistance. There was no significant difference between the two different media (HV agar vs. YEMED agar). From these spore suspension biocide treatments, we determined that biocide resistance was strain specific rather than clade specific. Overall, phenol treatment and isolation on $\mathrm{HV}$ agar does not appear to be specific for the isolation of $S$. violaceusniger clade members.

\section{Discussion}

Several S. violaceusniger clade members were isolated from the rhizospheric soil using the phenol pretreatment. It has been suggested that members of this clade are likely more difficult to culture from soil than other commonly isolated Streptomyces, and are difficult to isolate using conventional dilution plating [9]. Therefore, phenol pretreatment of soil combined with isolation on HV agar was used to select these specific clade members. HV agar, containing soil humic acid as the sole source of carbon and nitrogen, was developed by Hayakawa et al. [8] to specifically isolate actinomycetes of the clade. While treatment with phenol reduced the numbers of actinomycetes recovered on the plates, the phenol-resistant colonies that were isolated from $\mathrm{HV}$ agar were not all characterized as $S$. violaceusniger clade members, based upon their $16 \mathrm{~S}$ rDNA sequences (Table 3). Other Streptomyces isolates survived treatment with both biocides. Phylogenetic analysis clearly showed that the antifungal antibiotic producers were clustered into the $S$. violaceusniger clade, while those isolates that did not exhibit antifungal activities were clustered with non-clade members. The biocide survivability tests showed that, while spores of all of the clade members survived the two biocides, spores of non-clade members such as $S$. coelicolor M145 and S. lividans TK21 also survived. Therefore, we conclude that $S$. violaceusniger clade members are not specifically resistant to either 
phenol or hydrogen peroxide. Resistance appears to be strain specific and not clade specific. Thus, our results differ significantly from those of Hayakawa et al. [9]. There are, however, several of their experimental steps that we could not replicate. First, they used humic acids purified directly from the soil to make the HV agar, while we purchased humic acid from a chemical company. Second, we used different type strains for the biocide treatments. Third, while they identified their isolates using DNA-DNA hybridization methods and found them to be $S$. violaceusniger clade members, we used 16S rRNA gene sequences.

We have observed that Streptomyces that are isolated from different geographical regions and show strong broad-spectrum antifungal antibiotic activities are often members of the $S$. violaceusniger clade or they are closely related strains [2, 6, 13, 21]. Some of those were isolated from plant rhizospheres. When we identified the phenol-resistant strains obtained from this study, those that had broad-spectrum antifungal and antiyeast activity also turned out to be members of the $S$. violaceusniger clade. The strains that did not exhibit antifungal and antiyeast activities were found to be non-clade members. Our result does not support previous literature reports. We conclude that the biocide phenol pretreatment and humic acid vitamin agar isolation methods do not specifically enrich for the $S$. violaceusniger clade. We also conclude that it is more useful to simply screen isolates of broad-spectrum antifungal antiyeast activity in order to greatly increase the chances of isolating $S$. violaceusniger clade members.

Open Access This article is distributed under the terms of the Creative Commons Attribution Noncommercial License which permits any noncommercial use, distribution, and reproduction in any medium, provided the original author(s) and source are credited.

\section{References}

1. Atlas RM (1993) Handbook of microbiological media. CRC Press, Boca Raton, FL

2. Axelrood PE, Clarke AM, Radley R, Zemcov SJ (1996) Douglasfir root-associated microorganisms with inhibitory activity towards fungal plant pathogens and human bacterial pathogens. Can J Microbiol 42:690-700

3. Chamberlain K, Crawford DL (1999) In vitro and in vivo antagonism of pathogenic turfgrass fungi by Streptomyces hygroscopicus strains YCED9 and WYE53. J Ind Microbiol Biotechnol 23:641-646

4. Chamberlain K, Crawford DL (2000) Thatch biodegradation and antifungal activities of two lignocellulolytic Streptomyces strains in laboratory cultures and in golf green turfgrass. Can J Microbiol 46:550-558

5. Crawford DL, Lynch JM, Whipps JM, Ousley MA (1993) Isolation and characterization of actinomycete antagonists of a fungal root pathogen. Appl Environ Microbiol 59:3899-3905

6. Getha K, Vikineswary S (2002) Antagonistic effects of Streptomyces violaceusniger strain G10 on Fusarium oxysporum f.sp. cubense race 4: indirect evidence for the role of antibiosis in the antagonistic process. J Ind Microbiol Biotechnol 28:303-310

7. Gonzalez A (2004) Investigation of the distribution, diversity, and dynamics of mesophilic and thermophilic actinomycetes that produce hydrolytic enzymes and antifungal metabolites (Ph.D. thesis). University of Idaho, Moscow, ID

8. Hayakawa M, Nomura S (1987) Humic acid-vitamin agar. A new medium for the selective isolation of soil actinomycetes. J Ferment Technol 65:501-509

9. Hayakawa M, Yoshida Y, Iimura Y (2004) Selective isolation of bioactive soil actinomycetes belonging to the Streptomyces violaceusniger phenotypic cluster. J Appl Microbiol 96:973-981

10. Kieser T, Bibb MJ, Buttner MJ, Chater KF, Hopwood DA (2000) Practical Streptomyces genetics. The John Innes Foundation, Norwich

11. Labeda DP, Lyons AJ (1991) The Streptomyces violaceusniger cluster is heterogeneous in DNA relatedness among strains: emendation of the description of $S$. violaceusniger and Streptomyces hygroscopicus. Int J Syst Bacteriol 41:398-401

12. Lane DJ (1991) 16S/23S rRNA sequencing. In: Stackebrandt E, Goodfellow M (eds) Nucleic acid techniques in bacterial systematics. Wiley, Chichester

13. Saintpierre D, Amir H, Pineau R, Sembiring L, Goodfellow M (2003) Streptomyces yatensis sp. nov., a novel bioactive streptomycete isolated from a New-Caledonian ultramafic soil. Antonie Van Leeuwenhoek 83:21-26

14. Sembiring L, Ward AC, Goodfellow M (2000) Selective isolation and characterisation of members of the Streptomyces violaceusniger clade associated with the roots of Paraserianthes falcataria. Antonie Van Leeuwenhoek 78:353-366

15. Swafford DL (2002) PAUP*, 4th edn. Sinauer, Sunderland, MA

16. Thompson JD, Gibson TJ, Plewniak F, Jeanmougin F, Higgins DG (1997) The CLUSTAL_X windows interface: flexible strategies for multiple sequence alignment aided by quality analysis tools. Nucleic Acids Res 25:4876-4882

17. Trejo-Estrada SR, Paszczynski A, Crawford DL (1998) Antibiotics and enzymes produced by the biocontrol agent Streptomyces violaceusniger YCED-9. J Ind Microbiol Biotechnol 21:81-90

18. Trejo-Estrada SR, Sepulveda IR, Crawford DL (1998) In vitro and in vivo antagonism of Streptomyces violaceusniger YCED 9 against fungal pathogens of turfgrass. World $\mathrm{J}$ Microbiol Biotechnol 14:865-872

19. Tripathi CKM, Praveen V, Singh V, Bihari V (2004) Production of antibacterial and antifungal metabolites by Streptomyces violaceusniger and media optimization studies for the maximum metabolite production. Med Chem Res 13:790-799

20. Williams ST, Goodfellow M, Anderson G (1989) Genus Streptomyces Waksman and Henrici, 1943, 339AL. In: Williams ST, Sharpe ME (eds) Bergey's manual of systematic bacteriology, vol 4. Springer, New York, pp 2452-2492

21. Wirth S, Ulrich A (2002) Cellulose-degrading potentials and phylogenetic classification of carboxymethyl-cellulose decomposing bacteria isolated from soil. Syst Appl Microbiol 25:584-591 